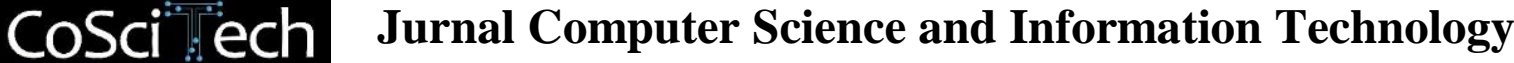
(CoSciTech)

\section{Implementasi steganografi EOF (end of file) pada file image}

\author{
Hari Sepdian ${ }^{1}$, Yulia Fatma ${ }^{2}$, Soni ${ }^{3}$, Yoze Rizki ${ }^{4}$ \\ Email: ${ }^{1}$ hari.sepdian@student.umri.ac.id, ${ }^{2}$ yuliafatma@umri.ac.id, ${ }^{3}$ soni@umri.ac.id, ${ }^{4}$ yozerizki@umri.ac.id
}

${ }^{1234}$ Teknik Informatika, Fakultas Ilmu Komputer, Universitas Muhammadiyah Riau

Diterima: Oktober 2021 | Direvisi: November 2021 | Disetujui: Desember 2021

(C)2021 Program Studi Teknik Informatika Fakultas Ilmu Komputer,

Universitas Muhammadiyah Riau, Indonesia

\begin{abstract}
Abstrak
Steganografi adalah salah satu teknik yang digunakan untuk menyembunyikan data ke dalam data digital lainnya. Kerahasian dan keamanan menjadi aspek penting yang dibutuhkan pada proses pertukaran pesan atau informasi baik melalui jaringan ataupun internet. Kriptografi dan steganografi dapat diimplementasikan pada aplikasi untuk mengamankan pesan dengan media gambar. Biasanya teknik yang sering digunakan yaitu dengan melakukan enkripsi terhadap pesan terlebih dahulu, kemudian menyisipkannya ke sebuah media cover. Penelitian ini menggunakan jenis data yaitu berupa pesan teks yang disembunyikan atau disisipkan dan media penampung yaitu berupa citra digital. Salah satu metode steganografi yang digunakan yaitu EOF (End of File). Penelitian ini merancang suatu sistem penyisipan data untuk disisipkan di baris terakhir media penampung. Tujuan pembuatan Penelitian ini untuk mendapatkan hasil citra stego yang baik. Berdasarkan hasil penelitian pada gambar yang digunakan sebagai media penyimpanan pesan (plaintext), menunjukan semakin panjang plaintext yang disisipkan semakin besar ukuran gambar yang digunakan sebagai media penyimpanan. Penyisipan pesan pada gambar sebagai media penyimpanan menggunakan metode End Of File ini memiliki kriteria yang baik. Yakni memiliki imperceptibility (keberadaan gambar embeded di dalam gambar stego tidak dapat dideteksi secara kasat mata), fidelity (mutu gambar secara kasat mata tidak berubah walaupun setelah mengalami proses penyisipan gambar), recovery (gambar stego dapat diekstrak kembali) dan padat menampung jumlah karakter yang relatif panjang tergantung dimensi gambar yang digunakan.
\end{abstract}

Kata kunci: eof, gambar, steganogafi, end of file.

\section{Implementation of EOF (end of file) steganography on image files}

\begin{abstract}
Steganography is a technique used to hide data into other digital data. Confidentiality and security are important aspects needed in the process of exchanging messages or information either through the network or the internet. Cryptography and steganography can be implemented in applications to secure messages with image media. Usually the technique that is often used is to encrypt the message first, then insert it into a media cover. This study uses the type of data that is in the form of hidden or inserted text messages and the container media in the form of digital images. One of the steganographic methods used is EOF (End of File). This study designed a data insertion system to be inserted in the last line of the container media. The purpose of this research is to get a good stego image. Based on the results of research on images used as message storage media (plaintext), it shows that the longer the inserted plaintext, the larger the image size used as storage media. The insertion of messages in images as storage media using the End Of File method has good criteria. Namely, it has imperceptibility (the existence of the embedded image in the stego image cannot be detected by naked eye), fidelity (the image quality does not change with the naked eye even after undergoing the image insertion process), recovery (the stego image can be extracted again) and densely accommodates the number of characters required, relatively long depending on the dimensions of the image used.
\end{abstract}

Keywords: eof, image, steganogaphy, end of file

\section{Pendahuluan}

Banyak sekali kota di seluruh bagian bumi ini, menyebabkan penggunaan media digital semakin banyak digunakan. Penyampaian informasi pada media digital dipilih karena waktu pengiriman yang cepat dan penggunaannya yang semakin mudah. Penggunaan internet (interconnection network) memang berkembang terus menjadi media komunikasi data yang sangat populer. Kecepatan dan kemudahan didalam penggunaan fasilitas yang disediakan lengkap adalah kelebihan internet, serta harus diakui oleh semua kalangan masyarakat pengguna internet pada zaman sekarang atau sering disebut dengan istilah jaman now 
baik itu kalangan anak-anak, remaja, dewasa hingga orang tua. Permasalahan yang berhubungan dengan masalah keamanan informasi muncul, ketika seseorang ingin mengirimkan informasi yang bersifat rahasia rentan sekali teradap pencurian. Metode EoF dikenal juga sebagai algoritma injeksi, teknik ini secara langsung menambahkan pesan pada akhir file. Keberhasilan algoritma injeksi menyisipkan pesan pada media penampung akan mempertahankan kualitas media penampung. Tetapi metode ini secara signifikan akan mempengaruhi ukuran file stego, karena penyisipan pesan diletakkan di akhir berkas(Lulu, Imam \& Yuli, 2018).

Alasan diadakan penelitian ini adalah untuk menyembunyikan pesan rahasia menggunakan steganografi metode EOF pada media gambar sehingga pesan yang dikirim tetap aman.

Permasalahan yang dibahas dalam penelitian ini yakni sebagai berikut:

1) Informasi yang disembunyikan berupa teks.

2) Media penampung yang digunakan untuk menyembunyian pesan adalah gambar berwarna dengan format JPG.

3) Penelitian ini tidak membahas perbedaan maupun kelemahan algoritma EOF (End Of File) dengan yang lain

4) Bahasa pemrograman yang digunakan adalah visual basic.

Berdasarkan penjelasan pada latar belakang yang telah dikemukakan, maka rumusan masalahnya adalah sebagai berikut:

1) Bagaimana mengirimkan informasi yang bersifat rahasia dengan aman.

2) Bagaimana melakukan perbandingan proses steganografi pesan dengan algoritma dan End Of File(EOF) untuk menyimpan pesan pada gambar.

\section{Metode Penelitian}

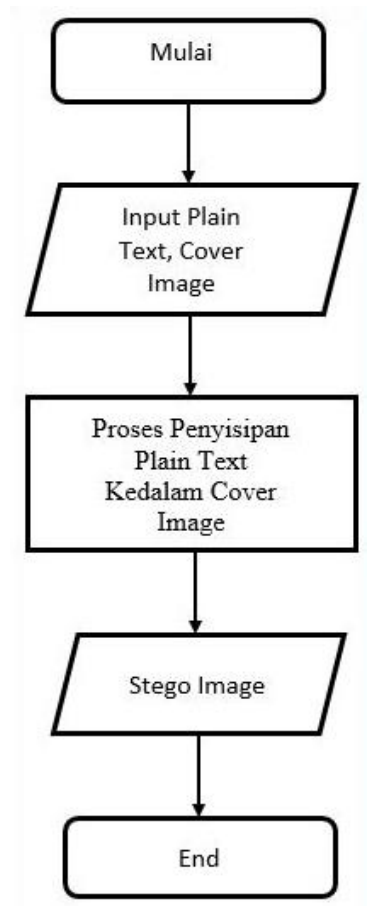

Gambar 1 Flowchart Penyisipan Pesan Rahasia

Pada gambar 1 diatas terlihat beberapa tahapan proses untuk yang mana dimulai dari user masuk kehalaman menu penyisipan aplikasi. Kemudian memasukan plaintext yang ingin disembunyikan. Pilih gambar yang ingin disisipkan pesan, dilanjutkan proses EOF yang manatahapan ini pesan akan dimasukan ke bit yang terakhir dari gambar. Setelah proses ini berhasil maka akan menghasilkan gambar yang berisipesan. pesan dapat disimpan untuk mengakhiri proses penyisipan.

Pada pengujian sistem adapun rencana pengujian atau sekenario pengujian yaitu :

1) Melakukan pemilihan gambar yang akan dikirim.

2) Menyisipkan pesan pada gambar berwarna.

3) Mengambil file gambar yang disisipkan pesan

4) Melakukan ekstraksi gambar yang diterima

5) Membandingkan perubahan yang terjadi pada gambar sebelum dansesudah perubahan 
Untuk melakukan proses penyisipan seperti dibawah :

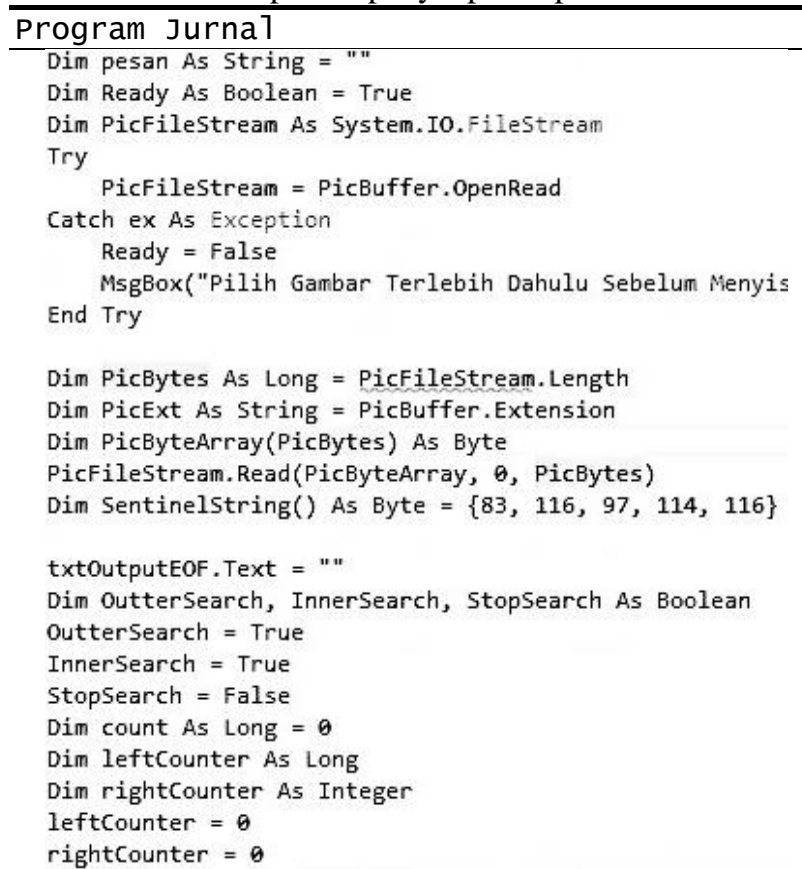

Adapun kebutuhan fungsional yang merupakan kebutuhan perangkat keras, perangkat lunak, serta pengguna sistem tersebut.

Tabel 1 Tabel Software dan Hardware Pendukung

\begin{tabular}{|c|c|c|}
\hline & Perangkat & Client \\
\hline \multirow[t]{2}{*}{1} & Processor & Intel(R) Core(TM) i5 \\
\hline & & 4210U CPU @ $1.70 \mathrm{GHz} 2.40 \mathrm{GHz}$ \\
\hline 2 & Ram & $4 \mathrm{~Gb}$ \\
\hline 3 & Monitor & 14 \\
\hline 4 & Harddisk & $500 \mathrm{~Gb}$ \\
\hline 5 & Koneksi Internet & Ada \\
\hline 6 & Sistem Operasi & Microsoft Window 764 bit \\
\hline \multirow[t]{2}{*}{7} & Program & Visual basic \\
\hline & & Google chrome \\
\hline
\end{tabular}

\section{Hasil dan Pembahasan}

1) Langkah Perhitungan EOF

P’roses perhitungan nilai piksel gambar meggunakan metode EOF (End Of File), pertamanya baca nilai ASCII gambar yang digunakan, kemudian ubah nilai gambar tersebut menjadi kode, kemudian sisipkan di akhir nilai pesan. Berikut ini adalah langkah perhitungan EOF dari hasil mixcolumns.

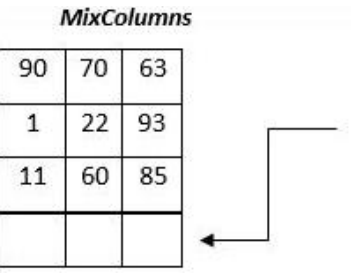

\begin{tabular}{|c|c|}
\hline$A$ & 65 \\
\hline$K$ & 75 \\
\hline$U$ & 85 \\
\hline
\end{tabular}

Gambar 2 Ilustrasi EOF

2) Implementasi Menu Sisipkan 


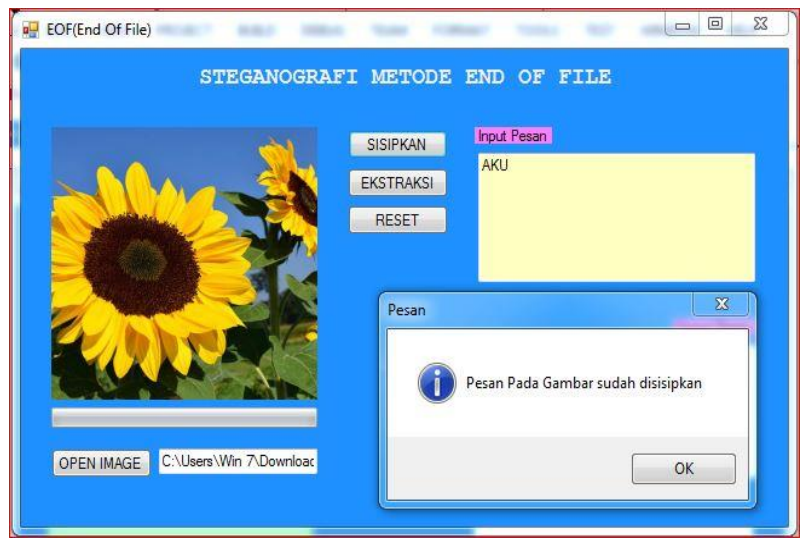

Gambar 3 Implementasi Menu proses penyisipan

3) Implementasi Menu Ekstraksi

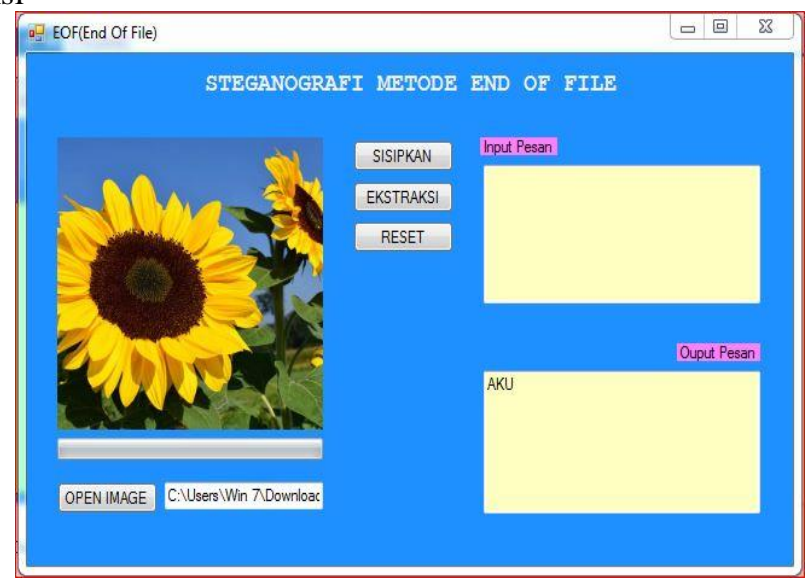

Gambar 4 Implementasi Menu proses penyisipan

4) Pengujian

Pada tahap ini dilakukan pengujian pada sistem sesuai dengan tujuan penelitian untuk menghasilkan untuk menyembunyikan pesan rahasia yang telah di sisipkan dengan menggunakan steganografi metode EOF pada media gambar, dengan data masukan yang diproses adalah data teks.

Untuk mendukung pengujian, diskenariokan terdapat 2 pihak yang ingin berkomunikasi, pengirim pesan sebut saja A, ke pihak penerima yaitu B. Skenario dapat berubah terbalik sesuai dengan pengujian penyisipan dan ekstraksi yang digunakan dengan gambar JPG, tabel 2 berikut akan memperlihatkan gambar yang akan digunakan pada pengujian.

\begin{tabular}{ccccc}
\multicolumn{5}{c}{ Tabel 2 Pengujian Penyisipan Pesan } \\
\hline No & Nama File & Penyisipan & Size & Keterangan \\
\hline 1 & Bunga Matahari.jpg & 100 karakter & $96.9 \mathrm{~Kb}$ & Berhasil \\
\hline 2 & Bunga Matahari.jpg & 500 karakter & $97.3 \mathrm{~Kb}$ & Berhasil \\
\hline 3 & Bunga Matahari.jpg & 100 karakter & $97.8 \mathrm{~Kb}$ & Berhasil \\
\hline
\end{tabular}

Dari tabel 2 pengujian yang dilakukan untuk meniyisipkan pesan kedalam gambar sebagai media penyimpan memiliki rata-rata penggunaan ukuran file gambar yang meningkat, dapat disimpulakan bahwa jumlah plaintext yang disisipkan kedalam gambar mempengarui ukuran pada gambar. Pada kenaikan size gambar yang menunjukan pola yang sama dilihat pada gambar diatas.

\section{Kesimpulan}

Berdasarkan hasil dari penelitian yang dilakukan dengan penyisipan pesan menggunakan steganorafi EOF, dengan gambar sebagai media penyimpanan menggunakan metode EOF (End Of File) maka diperoleh kesimpulan sebagai berikut :

1. Pesan rahasia yang telah dienkripsi berhasil disisipkan pada gambar JPG dengan menggunakan metode EOF (End Of File).

2. Berdasarkan hasil penelitian pada gambar yang digunakan sebagai media penyimpanan pesan (plaintext), menunjukan semakin panjang plaintext yang disisipkan semakin besar ukuran gambar yang digunakan sebagai media penyimpanan. 
3. Penyisipan pesan pada gambar sebagai media penyimpanan menggunakan metode End Of File ini memiliki kriteria yang baik. Yakni memiliki imperceptibility (keberadaan gambar embeded di dalam gambar stego tidak dapat dideteksi secara kasat mata), fidelity (mutu gambar secara kasat mata tidak berubah walaupun setelah mengalami proses penyisipan gambar), recovery (gambar stego dapat diekstrak kembali) dan padat menampung jumlah karakter yang relatif panjang tergantung dimensi gambar yang digunakan.

\section{Daftar Pustaka}

[1] Dwi Ratna Sari, Juli 2017, Perancangan Aplikasi Steganografi Pada Citra Digital Dengan Metode Bit Plane Complexity Segmentation (Bpcs), Medan. ISSN 2301-9425

[2] Bonifacius Vicky Indriyono.2016. Penerapan Keamanan Penyampaian Informasi Melalui Citra dengan Kriptografi Rijndael dan Steganografi LSB Information Security Through Imagery with Rijndael Cryptography, 228-241

[3] Hanifah Rahmi Fajrin. November 2016, Perbandingan Metode Untuk Perbaikan Kualitas Citra Mammogram. Yogyakarta, ISSN: 2252-4983

[4] Lulu Maftukhatul Jannah, Imam Santoso, Dan Yuli Cristyono, Maret 2018, Kinerja Steganografi Metode End Of File Pada Data Citra Digital, Semarang. ISSN: 2302-9927

[5] Sasmito, G. W., 2017. Penerapan Metode Waterfall Pada Desain Sistem Informasi Geografis Industri Kabupaten Tegal, $2(1), 6-12$.

[6] Hermawati, Fajar Astuti. Pengolahan Citra digital dan teori. Yogyakarta, Edisi, 2013, 1. Penerbit Andi

[7] Martono, Irawan, September 2013, Penggunaan Steganografi dengan Metode End of File (EOF) pada Digital Watermarking, Jakarta Selatan. ISSN 2302 $-3252$

[8] Johannes Petrus, Juli 2015, Implementasi Steganografi pada Citra dengan Metode Bit-Plane Complexity Segmentation Untuk Transformasi Data, Palembang. ISSN: 2354-5771

[9] Pandapotan, T. S., \& Zebua, T., 2016. Analisa Perbandingan Least Significant Bit dan End Of File Untuk Steganografi Citra Digital Menggunakan Matlab, (November), 11-12.

[10] Jane Irma Sari, Sulindawaty, Hengki Tamando Sihotang, Desember 2017, Implementasi Penyembunyian Pesan Pada Citra Digital Dengan Menggabungkan Algoritma Hill Cipher Dan Metode Least Significant Bit (Lsb), Medan. p-ISSN : 2088-3943 e-ISSN : 2580-9041 